\title{
Aspectos da patologização e pânico moral sobre o consumo de jogos de videogame
}

Aspects of pathologization and moral panic about the consumption of video games

\author{
Wagner da Silveirra Bezerra \\ wagnerbezerra@cienciaearte.com \\ Doutor em Comunicação Social (PUC-Rio). \\ Pesquisador independente do Grupo de \\ pesquisa em Interações Digitais - GrID/CNPq
}

\section{Resumo}

Baseado em breve revisão bibliográfica e excertos da tese ${ }^{1}$ "Só mais 5 minutos, pai!" Interação social em ambientes de jogos digitais (Bezerra, 2021), este artigo propõe a discussão crítica sobre alguns aspectos dos pressupostos de pesquisas e publicações que, sem o necessário aprofundamento, prestam-se sobretudo à difusão de pânico moral que sustentam perspectivas alarmistas que preconizam a patologização do consumo de videogames.

Palavras-chave: interações sociais; game studies; videogames; ecologia das mídias.

\begin{abstract}
Based on a brief bibliographical review and excerpts from the thesis "Só mais 5 minutos, pai!" Interação social em ambientes de jogos digitais (Bezerra, 2021), this article proposes a critical discussion on aspects of the presuppositions of research and publications that, without the required deepening, lend themselves, chiefly, to the dissemination of moral panic that supports alarmist perspectives that advocate the pathologization of video game consumption.
\end{abstract}

Keywords: social interactions; moral panic; game studies; media ecology.

\footnotetext{
${ }^{1}$ Tese defendida em maio de 2021, no Programa de Pós-Graduação em Comunicação Social da PUC-Rio.

DIGNIDADE RE-VISTA | ISSN2525-698X| 2021 | V. VIII | N. 13 |Pacto Educativo Global: a busca por ressignificar a educação. Pastoral Universitária Anchieta PUC-RIO.
} 


\section{Introdução}

Ao investigar os efeitos sociais do consumo de games, pesquisadores/as (KHALED, 2018; ALVES, 2005) têm se deparado com supostas aproximações entre as narrativas de jogos digitais que simulam cenas de violência, guerras e variações de combate, e situações da vida cotidiana de jogadores/as em ambientes extrajogo. Algumas linhas de discussão buscam relacionar a quantidade de horas que jogadores/as de videogame passam em imersão nas interações on-line e off-line entre pares e em jogos individuais, com o possível deslocamento da narrativa ficcional que contém violência para o mundo da vida.

Lynn Alves (2005) estudou os modos como um grupo de gamers estabelece as relações entre os jogos digitais, especialmente aqueles que contêm narrativas violentas, e a vida privada dos informantes da pesquisa em situações relacionadas aos jogos ou não. Uma das perspectivas da observação era que a simulação da violência contida nos games atuem de forma "catártica" funcionando como uma espécie de válvula de escape para canalizar as tensões cotidianas dos jovens observados.

Em outras palavras, como experiência apartada da realidade pelo sistema, lógica e regras do videogame, a violência, comumente vista em perspectiva negativa, ganha novo sentido e "passa a ser considerada de forma construtiva, como um dos motores propulsores do desenvolvimento afetivo e cognitivo dos sujeitos" (Alves, 2005, p.229). Nesse sentido, os games atuam como linguagem e ambientes de aprendizados, lugares seguros para extravasar e ressignificar dificuldades pessoais comuns das pessoas como medos e angústias.

Alves (2005) assinala que, em resposta à sua indagação inicial de pesquisa, ou seja, se os jogos considerados violentos geram comportamentos violentos, "os sujeitos da pesquisa em nenhum momento fazem a transposição do universo ficcional dos jogos para seu cotidiano" (p.236). Sob o ponto de vista da autora, o que alguns autores consideram "games violentos" pode estar baseado em

(...) uma beleza estética nas diferentes telas que apresentam ações violentas e o desenvolvimento de estratégias e habilidades presentes nesse tipo de jogo. Percebe-se, então, que essa interação pode estimular a construção de novas possibilidades (...) permite criar novas estratégias e intercambiar soluções para os desafios, tanto nos games que envolvem apenas dois jogadores por jogada, como naqueles que podem ser jogados com múltiplos usuários, nos quais as trocas podem acontecer em um mesmo espaço geográfico ou na rede (Alves, 2005, p.31).

Considerando que, no biênio 2020/2021, uma crise sanitária sem precedentes alterou por

DIGNIDADE RE-VISTA | ISSN2525-698X| 2021 | V. VIII | N. 13 |Pacto Educativo Global: a busca por ressignificar a educação. Pastoral Universitária Anchieta PUC-RIO. 
completo as formas de mediações tecnológicas virtuais na vida privada, discutir os limites temporais que o ser humano destina às interações on-line requer extraordinária parcimônia. É notório que, em momentos como o atual, os modos de brincar, aprender e a noção de equilíbrio entre o tempo destinado ao estudo, ao trabalho, ao tempo livre dedicado ao lazer foram drasticamente afetados.

Portanto, inexoravelmente, durante a pandemia provocada pelo novo coronavírus que provoca a doença denominada Covid-19, os jogos digitais e outros ambientes midiáticos passaram a ocupar uma fatia ainda maior da paisagem cotidiana, tornando-se ainda mais consumidos. Um aumento de consumo motivado, entre outros fatores, pela possibilidade de, através dos jogos digitais, tornar próximo o que estava fisicamente afastado e, desse modo, compensar as ausências e distanciamentos sociais. Quando boa parte das interações humanas são necessariamente mediadas digitalmente, os videogames podem aproximar usuários/as e conectar, unir, quem se encontra distante ao oferecer a "sensação de presença na ausência" (Silva, 2017, p.128).

Mais de uma década antes de a população mundial ser afetada pela explosão de consumo tecnológico que ocorreu devido ao isolamento social imposto pelo enfrentamento à pandemia, Elias e Dunning (1992) e Dumazedier (1962) classificaram a variável tempo como fato social e chamaram atenção sobre o que denominaram por "anatomia do tempo" ou do "organograma do tempo" (Silva, 2008). Ou seja, como o conceito "tempo" é subdividido e distribuído entre as diversas opções oferecidas pela vida em sociedade.

Esses autores demonstraram que os processos de socialização são marcados pelas temporalidades que lhes dão substâncias. Segundo essa perspectiva e em concordância com o ponto de vista do teórico Marshall Mcluhan, a organização, ou seja, as opções e escolhas que determinam a forma como o tempo é utilizado, deve ser examinada não apenas pelo viés quantitativo, mas, principalmente, em função dos hábitos sociais que envolvem, em especial, a convivência com as mídias como extensões do ser humano. Essa perspectiva sugere uma reflexão sobre "o tempo tal como é constituído por cada cultura e vivido por cada um" em sociedade (Winkin, 1998, p.95).

De acordo com a Pesquisa Game Brasil² (2019), um grande número de gamers, em

\footnotetext{
${ }^{2}$ Pesquisa realizada desde 2013, atualmente envolvendo as empresas Sioux Group, Go Gamers, Blend New Research e ESPM, cujo objetivo é trazer dados e análises sobre o cenário atual do mercado de games, enfocando

DIGNIDADE RE-VISTA | ISSN2525-698X| 2021 | V. VIII | N. 13 |Pacto Educativo Global: a busca por ressignificar a educação. Pastoral Universitária Anchieta PUC-RIO.
} 
diversos países, adolescentes em especial, almejava alcançar a profissionalização nos eSports (jogos digitais profissionais), através da busca por melhorar o desempenho nas competições de jogos digitais, tornando-se pro-player (jogadores profissionais). Como pré-requisito para alcançar ou mesmo tentar atingir o patamar técnico necessário para competir em torneios regionais, nacionais ou internacionais, é preciso que usuários/as de videogames realizem horas e horas de treinamento e, assim, adquiram competências específicas de acordo com o jogo ou a modalidade, visando galgar posições nas grandes competições conforme os critérios de ranqueamento de cada competição.

No Brasil, o jogo League of Legends (LOL) é um dos que mais atraem competidores, que sonham com a profissionalização. De acordo com as regras do LOL, a inatividade do jogador é um dos critérios que acarreta a perda de posições no ranking das ligas (Diamante, Mestre, Grão-Mestre e Desafiante) e hierarquiza jogadores/as dessa modalidade (Fortim et al., 2019).

Ao adquirir determinado número de vitórias, gamers competidores/as conquistam acesso às ligas que possibilitam aos/às mais bem colocados/as ascenderem nas respectivas categorias e obterem visibilidade junto a clubes contratantes e patrocinadores de competidores/as proplayer.

Nesse caso, o volume de tempo que usuários/as aspirantes a pro-player dedicam aos videogames, ao invés de ameaça ou risco de desenvolver "dependência” pelo hábito de jogar, pode representar oportunidade de ascensão social. Por outro lado, o esforço para manter-se no melhor nível das competições, acompanhado de horas e horas de treinamento, vitórias e derrotas, pontos ganhos ou perdidos, são fatores que podem gerar nervosismo ou angústia, comuns a competidores/as, como em qualquer outra prática esportiva.

Há um debate, até certo ponto "maniqueísta", que aborda ocorrências tipificadas como casos de "vício" e/ou "dependência" entre jogadores/as de videogame no mundo, supostamente relacionadas ao quantitativo de tempo destinado ao consumo dos jogos, em função das alterações ambientais contemporâneas. Ao discutir essa questão, considero relevante redobrar a atenção para não tomarmos como dadas algumas conclusões que podem conduzir, em seu tecido discursivo, a vieses morais e interesses econômicos ou ações de marketing político ou editorial.

hábitos de consumo nas plataformas de jogos e tendências de comportamento e preferências. https://www.pesquisagamebrasil.com.br/pt/

DIGNIDADE RE-VISTA | ISSN2525-698X| 2021 | V. VIII | N. 13 |Pacto Educativo Global: a busca por ressignificar a educação. Pastoral Universitária Anchieta PUC-RIO. 


\section{A propagação do pânico moral}

Embora alguns propagadores de pânico moral sustentem que podem existir conexões diretas entre conteúdos midiáticos considerados violentos e a violência praticada por pessoas expostas a situações de conflito, considero que o mais importante é analisar os casos em suas singularidades, sem a pretensão de generalizar o fenômeno como válido para toda a sociedade. Nesse caso menciono "pânico moral" quando, por interesse particulares, "pessoa ou grupo de pessoas são definidas como ameaça aos interesses e valores sociais (...) sua natureza é apresentada de maneira estereotipada e caricaturada pela mídia de massa" (Khaled, 2018, p. 46).

Goldstein alerta que alguns dos "estudos sobre videogames violentos estão obnubilados por definições ambíguas, uma pesquisa mal planejada e a confusão permanente entre correlação e casualidade" (Goldstein apud Prensky, 2010, p.49). De acordo com esse autor, é preciso compreender que o arrebatamento provocado pelos jogos digitais, que "magnetiza" gamers de todas as idades, especialmente crianças e adolescentes, durante horas e horas de jogo a fio, "não é a violência, ou mesmo o tema aparente, isto é, construir, dirigir ou atirar. Em vez disso, o verdadeiro segredo, que faz nossos filhos dedicarem tanto tempo aos games, é o conhecimento que adquirem" (Prensky, 2010, p.28). Nesse caso, o autor se refere a um tipo de aprendizado espontâneo, não "forçado", cujos conteúdos fluem por um meio que é muito mais do que apenas passatempo, embora a partir do qual uma criança ou adolescente possa apenas brincar.

Embora possa-se inferir que a capacidade educativa dos meios pode ser utilizada com qualquer tipo de conteúdo, mais uma vez enfatiza-se que se faz necessário analisar caso a caso para que se possa estabelecer parâmetros mais conclusivos. De fato, os estudiosos ainda divergem sistematicamente sobre o que se aprende e o quanto se aprende durante os jogos digitais ou qualquer outra mídia. Cabe reflexionar sobre a ausência de crítica em parte dos estudos (game studies) quanto aos efeitos tidos como positivos do consumo de games, ou seja, se os jogos digitais podem ser poderosos instrumentos difusores de informações que promovem o desenvolvimento de capacidades e competências de usuários/as quando abordam temas considerados positivos, por que seria diferente quando oferecem conteúdos classificados como "violentos"?

Na perspectiva de Bennerstedt et al. (2012), os dois pontos de vista, ou seja, a capacidade

DIGNIDADE RE-VISTA | ISSN2525-698X| 2021 | V. VIII | N. 13 |Pacto Educativo Global: a busca por ressignificar a educação. Pastoral Universitária Anchieta PUC-RIO. 
educativa dos jogos digitais versus o caráter violento dos videogames, visto como perigo para usuários/as, compartilham uma lógica em comum: a de que o ato de jogar videogame favoreceria a transferência de elementos constitutivos dos ambientes de jogo para as situações do mundo da vida, além do jogo em si. Nesse caso, o conceito de "transferência" é utilizado como uma metáfora para aprendizagem, como se esta pudesse ser um "produto" que pode ser deslocado de uma situação socialmente localizada para outra em outro contexto.

$\mathrm{Na}$ perspectiva clínico-patológica, na ótica da chamada "ciberpsicologia"33 (Donard, 2015), se a transitoriedade entre as realidades virtual e não virtual vivenciada pelos gamers, por um lado, produz novas formas identitárias, vínculos sociais, aquisição de habilidades, por outro lado, em casos relacionados ao uso excessivo de jogos, pode gerar consequências que podem ser encaradas como patológicas. Um exemplo de transtorno que teria sido verificado no campo da ciberpsicologia, seria a inadaptação de jogadores/as ao continuum ir e vir gerado pelos intervalos entre momentos de jogo e não jogo, e vice-versa, a que gamers são submetidos/as durante contínuas sessões de videogames.

Em matéria jornalística, de viés claramente "aterrorizante", Bertolotto ${ }^{4}$ descreve episódios de dependência resultantes do excesso de tempo dedicado aos games, no Japão, relacionados a grupos que a reportagem rotulou por “ermitões urbanos”. Segundo a reportagem, esses grupos desencadearam, por meio do uso excessivo de games, uma série de sintomas clínicos relacionados às dificuldades em estabelecer limites entre a realidade digital e a realidade não digital, gerando com isto sintomatologias complexas que vão da autorreclusão à incapacidade de lidar com o mundo tido como convencional.

Donard (2015, p. 385), ao observar usuários de games com sintomas de dependência de videogame, apontou que estes indivíduos, ao "desconectar da realidade ambiente para focar-se em uma realidade induzida por um suporte narrativo", necessitam de um processo de autoajuste para que seu funcionamento psíquico possa retornar aos padrões anteriores ao jogo. Processo que, segundo essa autora, poderia levar algumas horas ou se estender por alguns dias.

Na opinião de Fortim et al. (2019) jogos MMORPG (massively multiplayer online roleplaying game), cujo jogo mais acessado via internet é o World of Warcraft (WoW), podem tornarem-se mais "viciantes" que outros jogos, por conterem fatores como sofisticados sistemas

\footnotetext{
${ }^{3}$ Aplicação de novas tecnologias como auxílio no tratamento psicológico (Vascolcellos, 2013).

${ }^{4}$ Rodrigo Bertolotto é o jornalista responsável pela reportagem especial do portal UOL que abordou os fenômenos recorrentes resultantes do hiperconsumo de games entre jovens de 15 a 39 anos de idade em diversos países.

DIGNIDADE RE-VISTA | ISSN2525-698X| 2021 | V. VIII | N. 13 |Pacto Educativo Global: a busca por ressignificar a educação. Pastoral Universitária Anchieta PUC-RIO.
} 
de recompensas, proporcionarem intensa interações sociais entre usuários/as e facultarem aos/às jogadores/as um amplo leque de possibilidades criativas para composição dos avatares.

De acordo com Fortim et al. (2019), dois jogos destacam-se como potenciais geradores de "dependência" tecnológica

Os MMORPG são jogos on-line que se passam em universos persistentes (isto é, que continuam funcionando mesmo quando o jogador não está jogando), com milhares de jogadores interagindo uns com os outros e com o próprio jogo, formando alianças e desenvolvendo seus avatares. Os FPS são jogos de ação que são jogados com o ponto de vista do protagonista, e podem ser jogados nos modos de jogador único ou com múltiplos jogadores. (Fortim et al., 2019, p. 40)

Considero imprescindível mencionar que a Organização Mundial de Saúde utilizou como base para definir os transtornos psíquicos relacionados aos jogos digitais (CID-11) parâmetros semelhantes aos aplicados para diagnosticar casos de dependência por substâncias (químicas) e jogos de azar (jogos de apostas). Ou seja, a OMS descartou as significativas discrepâncias entre uma e outra "patologia". De acordo com a OMS, o diagnóstico de Gaming Discorder (GD) demanda identificação clínica, por meio de questionários, e deve constatar padrões recorrentes, caracterizados por alguns fatores específicos, embora subjetivos: 1. Ausência de controle do jogador relativo ao início, frequência, intensidade, duração, término e contexto; 2. Aumento de prioridade dada ao jogar ao ponto de se sobrepor a outros interesses e atividades diárias; 3. Para conclusão do diagnóstico, faz-se necessária a manutenção deste padrão concomitante a perdas em nível pessoal, profissional ou familiar (Fortim et al., 2019, p.35).

Ao reconhecerem a existência de discrepâncias entre perspectivas que discutem o modelo de diagnóstico adotado pela OMS para definir a CID-11, Fortim et al. (2019) afirmam que, para alguns autores, a chamada "dependência de games", na verdade, não existe, e que os sintomas, arbitrariamente descritos, estariam relacionados a outros tipos de transtornos emocionais preexistentes.

Por considerarem a inclusão pela OMS do "transtorno de jogo" na CID-11 medida inadequada e prematura, um grupo de 26 pesquisadores/as (Aaserth et al., 2017) que têm se dedicado a investigações científicas sobre direitos da criança e cidadania digital, aspectos problemáticos do uso das tecnologias, epidemiologia do uso saudável e não saudável de novas 
mídias, formularam e enviaram à OMS, em 9 de novembro de 2016, "Carta de preocupação", na qual apontam uma série de incongruências e vulnerabilidades, do ponto de vista científico, na pesquisa que embasou a formalização do transtorno "desordem de jogo" que patologiza o consumo de games.

O receio destes/as estudiosos/as (Aaserth et al., 2017) dos game studies baseia-se, entre outros fatores, nas premissas da fragilidade da pesquisa que embasou a nova CID-11 e no entendimento que tal medida possa ampliar um estigma, danoso para milhões de pessoas. Em especial, crianças e adolescentes que consomem jogos digitais de forma cotidiana e saudável e, a partir dessa nova patologia, correm o risco de serem "diagnosticados" como falso-positivos. Outro ponto levantado é o desperdício dos recursos da saúde pública em todos os continentes.

Ao criticar a categorização da OMS para transtornos relacionados aos jogos digitais, que possui embasamento similar à classificação de distúrbios vinculados à dependência de substâncias e jogos de azar, Fortim et al. (2019) acrescentam que "o tempo de uso dos games, ao contrário do que se pensava inicialmente, não é útil para diferenciar os jogadores que apresentam problemas (...) daqueles que têm os jogos como um comportamento saudável e benéfico" (Fortim et al., p.32, 2019).

Esses/as autores/as asseveram não ser adequado apontar as "novas tecnologias do entretenimento, incluindo os jogos digitais, com se fossem por si só causadores de dependência, pois, se fosse esse o caso, $100 \%$ das pessoas que jogam teriam problemas em função desse comportamento" (Fortim et al., p.63).

\section{A perspectiva de usuários/as ${ }^{6}$}

A paixão que consumidores/as de todas as idades, gêneros e etnias nutrem pelos videogames tem sido objeto de análises e reflexões que discutem a necessidade de estabelecer limites para o consumo de games. Será que o prazer que as experiências lúdicas proporcionadas pelas interações, através dos jogos digitais, gera dependência?

No fragmento a seguir, o adolescente Tião atribui sentidos positivos ao hábito a que ele se refere como "vício" e demonstra que a sua capacidade de decodificar a gramática dos jogos torna-o capaz de ressignificar o próprio hábito. Consumo que inicia pelo entretenimento, mas

\footnotetext{
${ }^{5}$ A íntegra da Carta encontra-se disponível em: <https://akademiai.com/doi/abs/10.1556/2006.5.2016.088>. Consulta em: 10 jan 2021.

${ }^{6}$ Excertos dos dados oriundos dos grupos focais coletados para a Tese "[BLIND REVIEW]".

DIGNIDADE RE-VISTA | ISSN2525-698X| 2021 | V. VIII | N. 13 |Pacto Educativo Global: a busca por ressignificar a educação. Pastoral Universitária Anchieta PUC-RIO.
} 
que, a partir da reflexão crítica, ganha novas matizes, sentidos e significados que transcendem os conteúdos e vivências experienciadas através dos jogos. Segue o exemplo:

TIÃO (GF Tarde) De: 01:04:15 até: 01:12:16 - (...) Se você tem um espírito competitivo, mais acima do meu, você vai querer ganhar de todo jeito. E se você perde você vê e fala: eu quero ganhar na próxima [risos]. É aí que mora o vício. E nisso é que mora também o porquê da diversão (...) Isso é a mistura da empolgação, é a mistura da empolgação junto com a vontade. É aí que mora o vício (...) Eu, eu acho bom o meu vício. Eu gosto do meu vício. Porque emocionalmente eu acredito que eu tô melhorando cada vez mais em cima do meu vício. Porque eu, eu tenho assim um vício no LoL. Quando pô, que eu tinha né, porque agora não roda mais o PC. Eu tinha mais capacidade de interação com pessoas, eu gostava mais, eu tinha mais atenção. E, além disso, eu conseguia extrapolar a raiva que sei lá eu acumulava na escola (...) Ou, sei lá, um assunto triste. Por que será? Às vezes eu não, eu, sei lá, bateu um assunto triste, eu conseguia até que ficar melhor, jogando em cima disso. E por isso que virou um tipo de vício. E eu não acho ruim. Eu sempre gostei do meu vício porque em cima do jogo está melhorando eu como pessoa. É por isso que eu gosto do meu vício. Porque a maioria do tempo, sei lá, ou eu tô puto ou tô triste ou tô feliz. Eé assim que eu vou inteirando minha emoção no jogo (...) Pra mim, eu vejo é desenho desde criança. Então, esse é o maior vício que eu tenho. Como a gente tá falando de game, eu vou deixar esse vício pra lá [risos].

No próximo fragmento em destaque, Tomás correlaciona a expressão "vício" ao uso constante de videogames e menciona o esforço pessoal necessário para organizar as tarefas de casa e escolares:

TOMÁS (GF Tarde) De: 01:04:15 até: 01:12:16 - Ele vai pra escola, joga, não sai pra rua. Eu acho que isso é um pouquinho de vício porque você vai pra escola, você volta. A escola são o quê, quatro horas? Três? (...) Já chega em casa pensando no jogo, liga o jogo, fica o dia todo ali. Não sai pra comer, não sai pra fazer as necessidades básicas, higiene pessoal (...) Você tem que saber dividir.

Alguns estudiosos têm discutido a patologização do vício em games e outras tecnologias a partir de quadros sintomáticos que envolvem ausência de limites para o consumo, aliado a dificuldades no convívio social, isolamento, esquecimento de cumprir as tarefas pessoais, obesidade, dentre outros fatores determinantes para o enquadramento do jogador compulsivo no escopo de patologia consolidada pela OMS, que permitiria um diagnóstico clínico para o vício.

\section{Conclusão}

DIGNIDADE RE-VISTA | ISSN2525-698X| 2021 | V. VIII | N. 13 |Pacto Educativo Global: a busca por ressignificar a educação. Pastoral Universitária Anchieta PUC-RIO. 
Embora reconheça o valor do debate construído a partir de pontos de vista divergentes, mantendo o alinhamento teórico que embasa esta pesquisa, distancio-me da perspectiva avocada pela "ciberpsicologia" e, igualmente, da "demonização" e de julgamentos morais perpetrados em reportagens que abordam o consumo de jogos digitais de modo tão pouco profundo.

Em contraste, observando-se as singularidades de cada meio, Simões afirma que "assim como as revistas em quadrinhos, os filmes e as músicas, entre outros artefatos, os videogames devem ser analisados e compreendidos levando-se em consideração toda uma série de elementos de ordem contextual" (2020, p. 252), a partir dos quais resultam as representações relacionadas aos conteúdos e práticas proporcionadas por estas mídias.

Nesse sentido é necessário considerar que a desconfiança imposta aos videogames é metaforicamente permeada pelo imaginário popular, construído durante décadas a partir do mito que atribui à evolução tecnológica certa ameaça de dominação dos humanos pelas máquinas e, mais concretamente, pela "maneira de sentir das pessoas em relação aos computadores em geral" (Turkle, 1989, p.58).

Em momentos específicos, os debates sobre a correlação entre o consumo de determinados jogos apontados como de "caráter violento" e episódios de violência em si têm dividido a opinião de pesquisadores/as. A exemplo, tragédias ocorridas nos Estados Unidos, em 1999, em Columbine, estado do Colorado, e na Escola Estadual Professor Raul Brasil, em Suzano, SP, em 2019, quando jovens, franco-atiradores, causaram uma série de vítimas fatais.

No caso dos fatos citados, de acordo com Khaled (2018), estudos apontam justificativas relacionadas aos perigos contidos na imersão de usuários/as em jogos, como o DOOM - jogo 3D que simula tiros em primeira pessoa, frente à possível consequente adoção de práticas agressivas e antissociais na vida privada. Em perspectiva diversa, há quem considere que essa modalidade de jogo estimula o desenvolvimento de habilidades e competências como resolução de problemas e construção de estratégias (Prensky, 2010).

Khaled (2018) aponta que eventuais conexões entre violência e jogos digitais são, em grande parte, narrativas construídas por "grupos de pressão" para desfocar a opinião pública em relação a problemas estruturais, como desemprego e desigualdade social que, segundo esse autor, podem ser considerados como alguns dos verdadeiros fatores que promovem a violência, natural do ser humano, em sociedade. De acordo com esse autor, sempre que necessário, 
representantes do campo político e setores da imprensa valem-se de pesquisas acadêmicas que se prestam a corroborar a "criminalização cultural dos games, e também dos criadores e dos jogadores, para justificar seus pontos de vista. Trata-se de um complexo processo de difusão de pânico moral por reacionários culturais" (Khaled, 2018, p.14).

Reitero a importância de se buscar compreender, por exemplo, como usuários/as de videogames percebem as distinções entre o ambiente dos jogos e o mundo da vida, na escola e na família, além das questões comportamentais ou morais. Outrossim, recorro à perspectiva teórica das microssociologias no que se refere à prevalência dos próprios sujeitos para discutir essas e outras questões, a partir dos relatos de grupos de jogadores/as adolescentes, respeitando seu contexto sociocultural e demais particularidades que constituem o objeto.

Vale lembrar que todas as tecnologias produzidas a serviço da humanidade (do telefone ao trem, do automóvel ao avião, dos primeiros computadores à nanotecnologia...) competem entre si por atenção, acessos, tempo, recursos, cliques, consumidores/as..., mas, "principalmente pela predominância da sua visão de mundo, fomentando alterações sociais, institucionais e intelectuais" (Strate; Braga; Levinson, 2019, p.24). Portanto, considerando que o/a usuário/a é também conteúdo (McLuhan, 1964), tais alterações, das quais sobressai o significado das coisas da vida, é o que nos compete procurar compreender.

Concluindo, em resposta às abordagens que tencionam as discussões sobre os "perigos" e a necessidade da adoção de limites para o consumo de videogame, cabe refletir que as capacidades transformadoras e, certas vezes, "ameaçadoras", atribuídas pela sociedade às "novas" tecnologias e/ou às mídias, não chegam a ser uma novidade, tampouco revelam quaisquer significados absolutos a respeito dessas mídias ou tecnologias.

DIGNIDADE RE-VISTA | ISSN2525-698X| 2021 | V. VIII | N. 13 |Pacto Educativo Global: a busca por ressignificar a educação. Pastoral Universitária Anchieta PUC-RIO. 


\section{Referências bibliográficas}

AARSETH, E. et al. Scholars' open debate paper on the World Health Organization ICD-11 Gaming Disorder proposal. Journal of Behavioral Addictions, v. 6, n. 3, p. 267-270, 2017. Disponível em: <https://akademiai.com/doi/abs/10.1556/2006.5.2016.088>. Acesso em: 4 nov 2021.

ALVES, L. Game over: jogos electrônicos e violência. São Paulo: Futura, 2005.

BENNERSTEDT, U.; IVARSSON, J.; LINDEROTH, J. How gamers Manama aggression: Situating skills in collaborative computer games. International Journal of Computer-Supported Collaborative Learning, v. 7, n. 1, p. 43-61, 2012. Disponível em: <https://doi.org/10.1007/S11412-011-9136-6>; Acesso em: 12 set 2021.

BERTOLOTTO, R. Ermitões urbanos: o perfil de uma geração que usa a tecnologia como escape para se isolar da sociedade. UOL TAB, São Paulo, 19 jun 2017. Disponível em: https://tab.uol.com.br/ermitoes/\#ermitoes-urbanos. Acesso em: 3 jan 2021.

BEZERRA, Wagner da Silveira. "Só mais 5 minutos, pai!” Interação social em ambientes de jogos digitais. Tese (doutorado) - Pontifícia Universidade Católica do Rio de Janeiro, Departamento de Comunicação Social, 2021.

DONARD, V. Ciberpsicologia: desafios teóricos e clínicos. In: COSTA, A. P. et al. (Orgs.). Atas do $4^{\circ}$ Congresso Ibero-Americano em Investigação Qualitativa e do $6^{\circ}$ Simpósio Internacional de Educação e Comunicação. v.1. São Roque: Ludomedia, 2015. p. 384-389.

DUMAZEDIER, J. Vers une Civilisation du Loisir? Paris: Editions du Seuil, 1962.

ELIAS, N.; DUNNING, E. A Busca da Excitação, Lisboa: Defel. Difusão Editorial, 1992.

FORTIM, I.; SPRITZER, T. D.; LIMA, A. T. M; (coord) SANTAELLA, L. Games Viciam. Fato ou ficção? Barueri: Estação das Letras, 2019.

KHALED Jr., Salah H. Videogame e violência: cruzadas morais contra os jogos eletrônicos no Brasil e no mundo. Rio de Janeiro: Civilização Brasileira, 2018. 
BEZERRA, Wagner da Silveira. Aspectos da patologização e pânico moral sobre o consumo de jogos de videogame.

Dignidade Re-Vista, v.8, n.13, nov 2021.

McLUHAN, M. O meio é a mensagem. In: McLUHAN, M. Os meios de comunicação como extensão do homem (understanding media). São Paulo: Cultrix, 1964.

PESQUISA GAMES BRASIL. 2019. Disponível em: <https://www.pesquisagamebrasil.com.br/pesquisa-game-brasil-2019/>. Acesso em: 10 jan 2021.

PRENSKY, M. Não me atrapalhe, mãe - Eu estou aprendendo!: como os videogames estão preparando nossos filhos para o sucesso no século XXI e como você pode ajudar. São Paulo: Phorte, 2010. Disponível em: <http://pt.calameo.com/read/001601552c4cff6df6fed>. Acesso em: 5 .out 2021

SILVA, A. C. J. As narrativas interativas em videogames. In: PORTO, Ana Paula Teixeira; PORTO, Luana Teixeira (Orgs.). Novos olhares: leitura, ensino e mundo digital. URI; Frederico Westphalen, v. 8, p. 128-148, 2017.

SILVA, Alberto Nidio Barbosa de Araújo. Jogos, brinquedos e brincadeiras - Trajectos Intergeracionais. Universidade do Minho, Tese de Doutoramento em Estudos da Criança. Área de Especialização em Sociologia da Infância, 2008. Disponível em: http://repositorium.sdum.uminho.pt/handle/1822/13904 Acesso em: 5 out 2021.

SIMÕES, R. L. Estilo Doom: a polêmica dos videogames violentos. Antares: Letras e Humanidades, $\quad$ v. $12, \quad$ n. 28, dez 2020. Disponível em: <http://www.ucs.br/etc/revistas/index.php/antares/article/view/9204>; Acesso em: 4 nov 2021.

STRATE, L.; BRAGA, A.; LEVINSON, P. Introdução à ecologia das mídias. Rio de Janeiro: Ed. Puc-Rio; São Paulo: Loyola, 2019.

TURKLE, S. O Segundo Eu. Os Computadores e o Espírito Humano. Lisboa: Editorial Presença, 1989.

WINKIN, Y. A Nova Comunicação. Da teoria ao trabalho de campo. Campinas: Papirus, 1998. 